\title{
In memoriam Kurt Hess
}

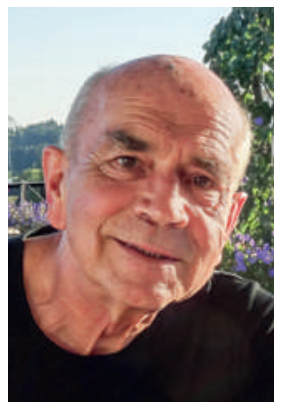

Dr. med. Kurt Hess 1.10.1943 - 29.1.2015
Kurt Hess ist am 29. Januar 2015 unerwartet verstorben. Wir haben einen grossartigen Menschen verloren.

In seinem Buch Das Prägende des Meerschweinchens. Jahreschronik eines ungeheilten Analysanden beschreibt er sich unübertrefflich selbst: «Geboren am 1.10.1943 in Zürich, Sohn einer lndustriellenfamilie. In Winterthur aufgewachsen. In der Mitte zweier Schwestern und zusammen mit der Grossmutter, einem Hund, zwei Kaninchen, einigen Goldhamstern, mehreren Schildkröten und einem Meerschweinchen.

Maschineningenieur-Studium an der ETH Zürich, Diplom 1967. 1969 Heirat mit der Schmuckgestalterin Johanna Dahm. 1970 Abschluss des Studiums der Wirtschaftswissenschaften an der Hochschule St.Gallen. 1972/73 USA-Aufenthalt und Absolvierung des Managementkurses an der Stanford University in KaIifornien. Seit 1976 wohnhaft in Zürich. Im selben Jahr Gründung einer eigenen Managementberatungs-Firma.

Konzeptautor und Drehbuchmitarbeiter für den preisgekrönten PR-Film «Hitting the Point».

1979-85 Medizinstudium an der Universität Zürich, Doktorat 1986. Von 1986 an entbehrungsreiche Tätigkeit als Assistenzarzt an verschiedenen Spitälern.

1992 Facharzt für Allgemeinmedizin und Eintritt in eine Zürcher Praxisgemeinschaft, die im Rahmen eines Pilotversuchs das schweizerische Modell der amerikanischen Health Maintenance Organisation (HMO) einführt.»

Zu diesem Zeitpunkt lernte ich Kurt Hess kennen. Wir mochten uns von der ersten Stunde an. Wir waren in Aufbruchsstimmung und wollten mit Managed Care verkrustete Strukturen in der medizinischen Versorgung auflösen. Es gab fast keine Tabus, an denen wir nicht rüttelten. Auf der Suche nach einer fairen, ehrlichen und wahrhaften Medizin erlebten wir eine unglaublich kreative Zeit.

Gemeinsam bauten wir die erste HMO-Praxis der Schweiz in Zürich Wiedikon auf. Mitte der goer Jahre traten wir in die Geschäftsleitung der Sanacare ein und festigten in diesem neuartigen Zusammenwirken von Kassen und Ärzten die ärztliche Souveränität.

1998 haben wir die EQUAM Stiftung gegründet. Kurt Hess hat sich in diesem Rahmen mit enorm viel Herzblut für die Förderung der Qualität in der ambulanten Medizin eingesetzt. In akribischer Detailarbeit hat er die Standards entwickelt, mit denen wir heute arbeiten. Einmal mehr hatte er sich einem schwierigen Projekt verschrieben. Aber gerade das war das Reizvolle für ihn. Es gibt nur wenige Personen in meinem Leben, mit denen ich so viel gescherzt und gelacht habe. Sehr, sehr viel gelacht: Wir haben nicht nur legendäre Bioresonanzergebnisse erzielt, sondern so ziemlich alles ausprobiert und auch wieder in Zweifel gezogen, was sich in unserem Wirkungsfeld auftat. Kurts Querdenken war erfrischend.

Kurt Hess liebte die Sprechstunde. Er war oft so fasziniert von all den Geschichten, dass er in arge Zeitnot kam. Und die Patienten liebten ihn, weil er so gut zuhören konnte. Er wollte den Themen auf den Grund gehen, war ehrlich und verlässlich, ein aufrichtiger Skeptiker. Und er war ein Realist, der ziemlich genau wusste, was sich in die Welt setzen liess und was nicht.

Kurt Hess liess sich von vielen Aspekten des Lebens faszinieren. Und er war faszinierend. Er hat die Menschen in seinen Bann gezogen. «So möchte ich daherkommen im Alter», hat mir vor kurzem ein Freund gesagt und damit Kurt gemeint, den er im Tram getroffen hatte. Vital, gebräunt, schalkhaft, ein attraktiver Mann. Um keine Antwort verlegen. Und wenn sie unpassend war, hat er das mit einem Lachen gleich wieder wettgemacht.

Kurt Hess ist mit seinem Velo mehrmals um die Welt gefahren, unglaublich. Er hatte diese unerschöpfliche Lebensenergie, diesen Lebenshunger, freute sich über das gute Gefühl im Körper nach Strapazen. Und es war manchmal zu viel. Aber er war stolz auf die vollbrachte Leistung. Es hat ihn ruhig und zufrieden gemacht.

Kurt Hess hat sich in den letzten Jahren zurückgezogen, hat eine Verpflichtung nach der anderen abgegeben. Als ob er gespürt hätte, dass das Leben gelebt ist, langsam zu Ende geht. Alle diese mühsamen Krankheiten waren keine schöne Aussicht.

Sein Tod hat ihm vieles erspart. Das zu wissen ist auch tröstlich. Aber ich hätte mir gewünscht, ihn noch lange als Freund der alten Tage und als treuen Weggefährten geniessen zu können. Kurt ist für uns viel zu früh gestorben. Für ihn selber war es vielleicht der richtige Moment.

Dr. med. Felix Huber 